\title{
Circulation of Sodium Sulfate Solution Produced During NiMH Battery Waste Processing
}

\author{
Antti Porvali ${ }^{1}$ (D) $\cdot$ Vivek Agarwal $^{1} \cdot$ Mari Lundström $^{1}$
}

Received: 4 March 2019 / Accepted: 21 May 2019 / Published online: 12 June 2019

(C) The Author(s) 2019

\begin{abstract}
Hydrometallurgical recovery of rare earth elements (REE) from NiMH battery waste can be performed using sulfuric acid leaching followed by selective precipitation as double salt $\left(\mathrm{REENa}\left(\mathrm{SO}_{4}\right)_{2} \cdot \mathrm{H}_{2} \mathrm{O}\right)$ by adding $\mathrm{Na}_{2} \mathrm{SO}_{4}$ as a precipitating agent. The formed double salts can then be further converted with $\mathrm{NaOH}$ solution to form REE hydroxides. However, present literature has paid little attention to how to minimize the consumption of reagents in this recovery process. In the current study, a process model was built using HSC Sim software, and metamodeling of the simulated flowsheet was conducted with the design of experiments (DOE), after which the basic functionality of the flowsheet was verified by experimental work, starting from sulfuric acid leaching of spent batteries. As the process is based on chemical circulation internally in the process, the objective was to investigate the accumulation of the elements in solution, specifically $\mathrm{Na}^{+}, \mathrm{K}^{+}, \mathrm{SO}_{4}{ }^{2-}$ ions and impurities liberated in the $\mathrm{NaOH}$ conversion step. It was found out that metamodeling could be utilized in obtaining first estimate of the process behavior, prior to any experiments. Flowsheet functionality with circulated solution was confirmed, obtaining at best $96.9 \%$ La recovery.
\end{abstract}

Keywords Flowsheet metamodeling $\cdot$ Hydrometallurgy $\cdot$ Recycling $\cdot$ Battery waste $\cdot$ Rare earths $\cdot$ Response surface methodology

\section{Introduction}

Nickel metal hydride $(\mathrm{NiMH})$ battery waste can be considered as an urban mineral due to the presence of valuable metals like $\mathrm{Ni}, \mathrm{Co}$, and rare earth elements (REE) [1]. In NiMH battery waste leaching experiments, sulfuric acid has often been employed as a lixiviant [2-5]. The key advantages of sulfuric acid are its stability and cost-effectiveness compared to other mineral acids such as $\mathrm{HCl}$ and $\mathrm{HNO}_{3}$. However, the usage of sulfuric acid in NiMH battery waste leaching poses simultaneous challenges and advantages due to limited REE sulfate solubility. Conversely, limited REE solubility can be taken as benefit when recovering REEs double sulfates after solidliquid separation. For example, the least soluble REE sulfate, lanthanum, has the solubility of $23 \mathrm{~g} / \mathrm{L}$ in water [6]. However, sodium and potassium hydroxide, present in electrolyte residues in the battery waste, can readily cause in situ precipitation during leaching due to formation of REE double sulfates, as per Eq. 1, which have a significantly more limited solubility (La $2.32 \mathrm{~g} / \mathrm{L}$ at $T=20{ }^{\circ} \mathrm{C}$ in $\mathrm{H}_{2} \mathrm{O}$ ) [7, 8], thus decreasing the

Mari Lundström

mari.lundstrom@aalto.fi

1 Aalto University, Otakaari 3J, 02150 Espoo, Finland total REE recovery [5]. However, the problem of in situ REE precipitation during the NiMH battery leaching can be circumvented by washing the $\mathrm{Na}$ and $\mathrm{K}$ containing electrolyte residues off the raw materials. Subsequently, this phenomenon can be taken of advantage in REE recovery after solid-liquid separation of battery waste and REE rich solution: sodium ions may be added into the pregnant leach solution (PLS) in order precipitate the REEs in bulk $[9,10]$ as a mixed double salt out from the solution at very low $\mathrm{pH}$ with minimal coprecipitation of $\mathrm{Ni}$ and other metals [11]. As shown in our previous study, the obtained precipitate is very crystalline and relatively pure and was obtained from acidic solution [5]. Before the dawn of solvent extraction in the wake of Manhattan Project, this was a commonly employed method of fractional precipitation of REEs [12]. This relatively easy separation method can still be extremely advantageous in the case of such a complex solution matrix with relatively high light REE concentrations (conc.), shown in Eq. 1:

$\mathrm{RE}^{3+}+2 \mathrm{SO}_{4}^{2-}+\mathrm{Na}^{+}+\mathrm{H}_{2} \mathrm{O} \rightarrow \mathrm{RENa}\left(\mathrm{SO}_{4}\right)_{2} \cdot \mathrm{H}_{2} \mathrm{O} \downarrow$

It must be noted that the chemistry behind the precipitation is more complex than what reaction (1) reveals, and most likely involves different complexes, such as $\mathrm{LaSO}_{4}{ }^{+}$and 
$\mathrm{La}\left(\mathrm{SO}_{4}\right)_{2}{ }^{-}$depending on ion activities and temperature. For example, the solubility of double salts has been shown to change in a complex manner based on $\mathrm{H}_{2} \mathrm{SO}_{4}$ concentration and subsequent bisulfate formation [7]. Another example is how the double sulfate solubility strongly decreases in the presence of excess sodium [11]. However, for the purposes of this study, the reaction is deemed sufficient as it is presented in this manner in other studies as well $[8,11]$, and can be utilized in calculating the process mass balance.

Once REEs have been precipitated as double sulfates as per Eq. 1 [5], the resulting double salt precipitate lacks applications without further treatment. Direct thermal treatment would generate sulfur dioxide emissions and likely require high temperatures in order to transform double sulfates into REE oxides. Furthermore, the precipitate contains $\mathrm{Na}$ ions, which would need to be removed by chemical treatment from the calcined REE product.

In the context of circularity of raw materials, it can be taken as a remarkable benefit if the sodium and sulfur present in the double salt could be reused instead of losing them into the process waste streams. In order to attempt to minimize reagent consumption, an aspect ignored in present $\mathrm{NiMH}$ recycling literature, flowsheet modeling, metamodeling, and experiments were utilized as tools to explore this subject. In this experimental and flowsheet modeling study, the double salts are converted by dissolution and precipitation in alkaline solution to hydroxides as shown by Abreu et al. [13] (Eq. 2) which are readily treatable, e.g., with total dissolution and solvent extraction, for further purification:

$$
\begin{aligned}
& \mathrm{RENa}\left(\mathrm{SO}_{4}\right)_{2} \cdot \mathrm{H}_{2} \mathrm{O}+3 \mathrm{NaOH} \rightarrow \mathrm{RE}(\mathrm{OH})_{3}+2 \mathrm{Na}_{2} \mathrm{SO}_{4} \\
& \quad+\mathrm{H}_{2} \mathrm{O}
\end{aligned}
$$

Simulation modeling is a practice of metamodeling. HSC Sim is based on modular process flowsheet modeling, and as such, it can be hard to derive equations of the model for optimization. In metamodeling, guided by principles of design of experiments (DOE), such flowsheet model is considered to be a black box: the user is aware of different inputs and the unit process (module) will produce the possible outputs without knowing anything about the module itself. Flowsheet simulation can also be either stochastic or deterministic [14]. In this paper, metamodeling of deterministic simulation is examined by applying response surface methodology [15] in conjunction with HSC $\mathrm{Sim}$, a modular process flowsheet simulation tool, which is an ideal target for such optimization investigations [16]. In this way, information of potentially complex inter-dependencies of process parameters can be attempted to explore in a more rigorous manner at process-wide level, and optimization can be attempted at localized parameter level [17]. As the original DOEs, such as the central composite design (CCD), were developed for real world applications, there are limitations in applying them to simulation modeling. In case of CCD, the limitation is due to the fitted model being a second-degree polynomial regression model. This can model local behavior efficiently, but global, non-polynomial behavior will be impossible to emulate [14]. Additionally, the purpose of DOE is to decrease the amount of required experimental runs, and at the same time maximize the obtained knowledge of the system that is being investigated. This is practical in real world situations where it can be unrealistic to perform hundreds of experiments. However, simulations are only limited by computing time, allowing vastly different quantity of "experiments" to be run. As such, statisticians and simulation experts have developed different statistical designs that can be more applicable to simulations rather than real world experimental work. These are not however discussed in this paper, but focus remains in applying the simpler CCD on this particular flowsheet.

In this work, the recirculation of the sodium and sulfate ions present in these double salts back to precipitation process was investigated. Several works have focused on recovery process, but little attention has been paid to resource efficiency issues caused by waste side streams. First, a process simulation flowsheet was created by using HSC Chemistry's Simulation module. Unit processes were created for each respective processing based on literature data, each step involving the formation and further treatment of the REE precipitate. The solutions generated during the REE double salt dissolution in $\mathrm{NaOH}$ were circulated back to the precipitation stage. The simulation was used to run several scenarios, where the acidity and REE contents of the pregnant leach solution (PLS) were varied, along with several other parameters that are critical to double salt precipitation, dissolution, and recirculation. By varying these parameters, observation on mass balance were performed. DOE was utilized in analyzing this data and in generating a metamodel of the flowsheet investigated. A quadratic model was fitted to a CCD based on the experimental design runs of the simulation, which also takes into account the second-degree interactions [15]. The created regression model was utilized in attempting to identify the optimal parameters for the recirculation of $\mathrm{Na}_{2} \mathrm{SO}_{4}$ solution. Subsequently, a round of chemical circulation experiments were performed in laboratory, starting from sulfuric acid leaching of NiMH battery waste. Losses borne in wash waters were recorded and dilution of the PLS measured. These experiments were performed in order to confirm the behavior observed in flowsheet modeling and metamodeling.

\section{Materials and Methods}

\subsection{Flowsheet Modeling}

Outotec's HSC 9.4.1 [18] was used in creating the flowsheet simulation model and published literature data. Minitab 17.1 
[19] was used in creating the quadratic regression models based on DOE. The flowsheet simulation model was composed of several unit processes, each handling their own specific processes. The general schematic of the flowsheet is shown in Fig. 1 and the most important functions and controllable parameters for each unit process are summarized in Table 1. The flowsheet can be divided into two parts: (I) the double salt precipitation $\left(\mathrm{Na}_{2} \mathrm{SO}_{4}\right.$ Prep. Tank, Precipitation Reactor \#1, and Filter \#1) and (II) the conversion of double salt into hydroxide ( $\mathrm{NaOH}$ Preparation Tank, Alkaline Conversion Reactor \#1, and Filter \#2). In addition, there is an additional unit process (bleed) for bleeding the solution in order to achieve balanced $\mathrm{Na}$ concentration in the main process.

In the Precipitation Reactor \#1, REEs are precipitated as double sulfates. The simulated unit process here contains an equation to simulate precipitation yield of $\mathrm{La}$ as a function of $\mathrm{Na} / \mathrm{REE}$ ratio, presented in Fig. 2 and Eq. 3. This equation is partially based on results of Kul et al. [20]. However, the precipitation kinetics and equilibrium are strongly depended on PLS ion concentrations and temperature which should be taken into consideration when modeling a unit process. The present unit process is modeled only at constant $T$ and $t$. This equation is not intended as an extremely accurate reflection of reality, but to mirror precipitation behavior. For example, for the purposes of non-linear regression fitting, a synthetic data point was added with assumption that when $\mathrm{Na} / \mathrm{REE}=0.5, \mathrm{La}$ recovery $\%=50 \%$.

Yield $=100-104.317 \cdot e^{-1.77958 *\left\{\frac{N a}{R E E}\right\}}$

Alkaline conversion Reactor \#1 does not contain a model akin to Eq. 3, but the reaction was assumed to progress to completion in $1 \mathrm{~h}$ according to Eq. 2 based on earlier work by Abreu and Morais (2010) [13].

\subsection{Flowsheet Metamodeling}

Face-centered central composite design (CCF) was utilized in the creation of regression models of the responses. The design

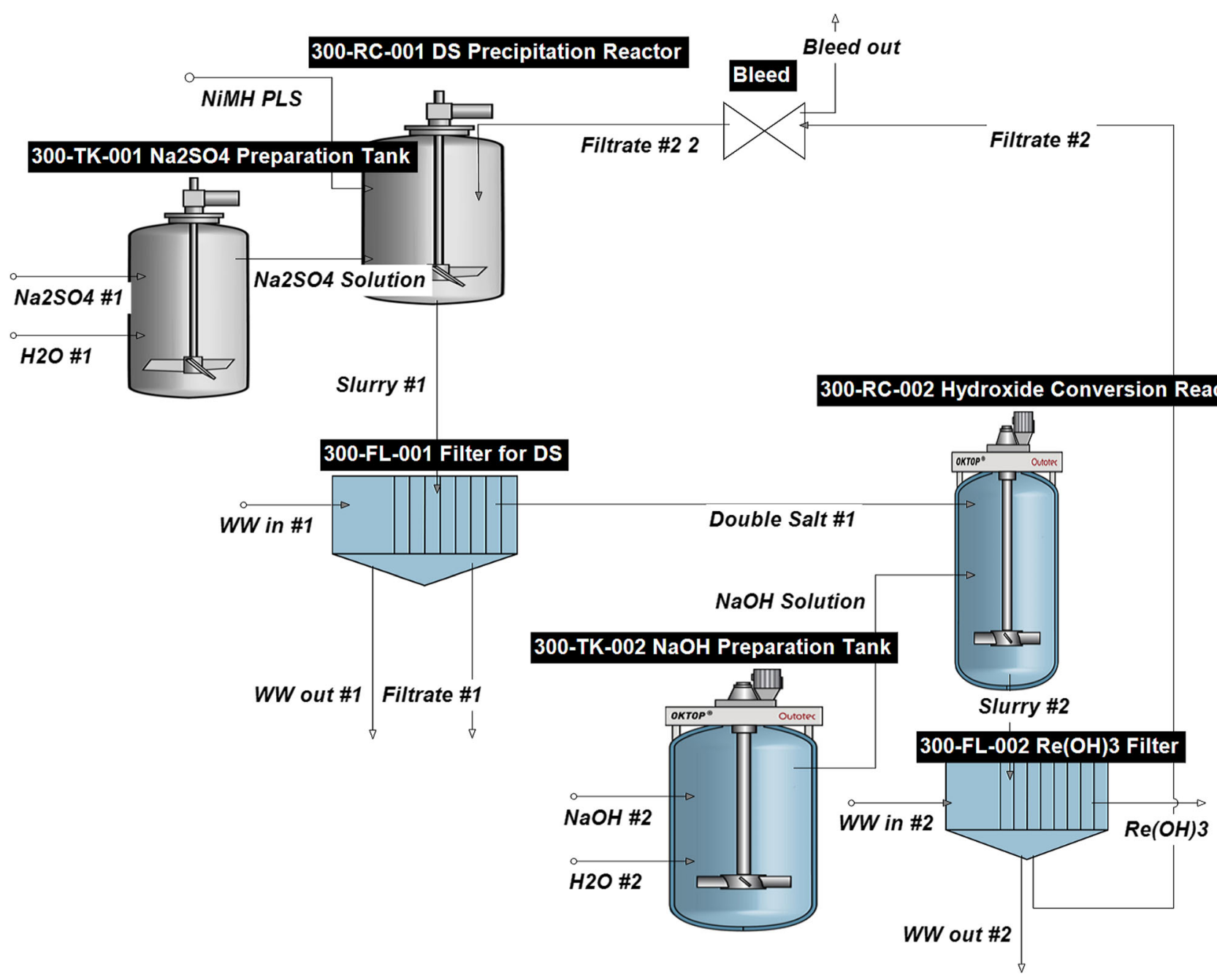

Fig. 1 Flowsheet of REE recovery step of PLS produced in leaching of spent NiMH batteries 
Table 1 Short summary of the contents of the unit processes and the investigated parameters

\begin{tabular}{|c|c|c|}
\hline Unit process name & Function & $\begin{array}{l}\text { Controllable } \\
\text { parameters }\end{array}$ \\
\hline $\begin{array}{l}\text { 300-RC-001 DS } \\
\text { Precipitation } \\
\text { Reactor }\end{array}$ & $\begin{array}{l}\text { Precipitation of double salts } \\
\text { from the solution. Contains a } \\
\text { regression model for REE } \\
\text { precipitation as a function of } \\
\text { Na/REE. In the model, a } 100 \\
\text { L/h PLS feed control was } \\
\text { created. }\end{array}$ & $\begin{array}{c}\text { PLS REE conc. } \\
\text { ( } \mathrm{g} / \mathrm{L}) \\
\text { PLS acid conc. } \\
\text { (mol/L) } \\
\text { PLS total } \\
\text { volume }(\mathrm{L} / \mathrm{h}) \\
\text { Initial } \mathrm{Na} / \mathrm{REE} \\
\text { ratio }(\mathrm{mol} /- \\
\mathrm{mol})\end{array}$ \\
\hline $\begin{array}{l}\text { 300-TK-001 } \\
\mathrm{Na}_{2} \mathrm{SO}_{4} \\
\text { Preparation Tank }\end{array}$ & $\begin{array}{l}\text { Preparation of fresh } \mathrm{Na}_{2} \mathrm{SO}_{4} \\
\text { solution. Controls the amount } \\
\text { of addition of } \mathrm{Na}^{+} \text {in } \\
\text { conjunction with } \\
\text { Precipitation Reactor \#1 and } \\
\text { Filtrate \#2. }\end{array}$ & $\begin{array}{c}\text { Molarity of } \\
\mathrm{Na}_{2} \mathrm{SO}_{4} \\
\text { solution } \\
(\mathrm{mol} / \mathrm{L})\end{array}$ \\
\hline $\begin{array}{l}\text { 300-FL-001 Filter } \\
\quad \text { for DS }\end{array}$ & Generic Outotec Filtration unit & $\begin{array}{c}\text { Cake moisture } \\
(\%) \\
\text { Washing } \\
\text { efficiency } \\
(\%)\end{array}$ \\
\hline $\begin{array}{l}\text { 300-RC-002 } \\
\text { Hydroxide } \\
\text { Conversion } \\
\text { Reactor }\end{array}$ & $\begin{array}{l}\text { Controls the dissolution of } \\
\text { double salt and precipitation } \\
\text { of hydroxides. The slurry } \\
\text { moves into Filter \#2. }\end{array}$ & $\begin{array}{c}3 \mathrm{NaOH} / \mathrm{REE} \\
\text { ratio } \\
(\mathrm{mol} / \mathrm{mol}) \\
\mathrm{L} / \mathrm{S} \mathrm{ratio}(\mathrm{mL} / \mathrm{g})\end{array}$ \\
\hline $\begin{array}{c}\text { 300-TK-002 NaOH } \\
\text { Preparation tank }\end{array}$ & $\begin{array}{c}\text { Preparation tank for } \mathrm{NaOH} \\
\text { solutions. It will adjust the } \\
\mathrm{NaOH} \text { volume based on } \\
\text { feedback from Alkaline } \\
\text { Conversion Reactor \#1. }\end{array}$ & \\
\hline $\begin{array}{l}\text { 300-FL-002 Filter } \\
\text { for } \mathrm{RE}(\mathrm{OH})_{3}\end{array}$ & Generic Outotec Filtration unit & $\begin{array}{c}\text { Cake moisture } \\
(\%) \\
\text { Washing } \\
\text { efficiency } \\
(\%)\end{array}$ \\
\hline Bleed junction & $\begin{array}{l}\text { Responsible for bleeding a } \\
\text { fraction of the recirculated } \\
\text { solution out of the process. } \\
\text { This is included in the model } \\
\text { in order to investigate how } \\
\text { bleeding affects the mass } \\
\text { balances of other unit } \\
\text { processes. }\end{array}$ & $\begin{array}{c}\text { Bleed fraction } \\
(\%)\end{array}$ \\
\hline
\end{tabular}

was composed of full two-level factorial design $\left(2^{7}\right)$. It is possible to use fractional factorial designs to create a CCD with resolution $\mathrm{V}$; however, there was no reason for doing so in the computer modeling in this particular instance. The design is augmented with star points at equidistance $\alpha$ from the center of the design. In CCF models, the distance of $\alpha=1$. The center points were replicated (18 times); however, the rest of the model was not as the replication of a deterministic model would not introduce any benefits due to the fact that there is no variation between replicates. The data obtained from the simulation was fitted into CCD in Minitab. The

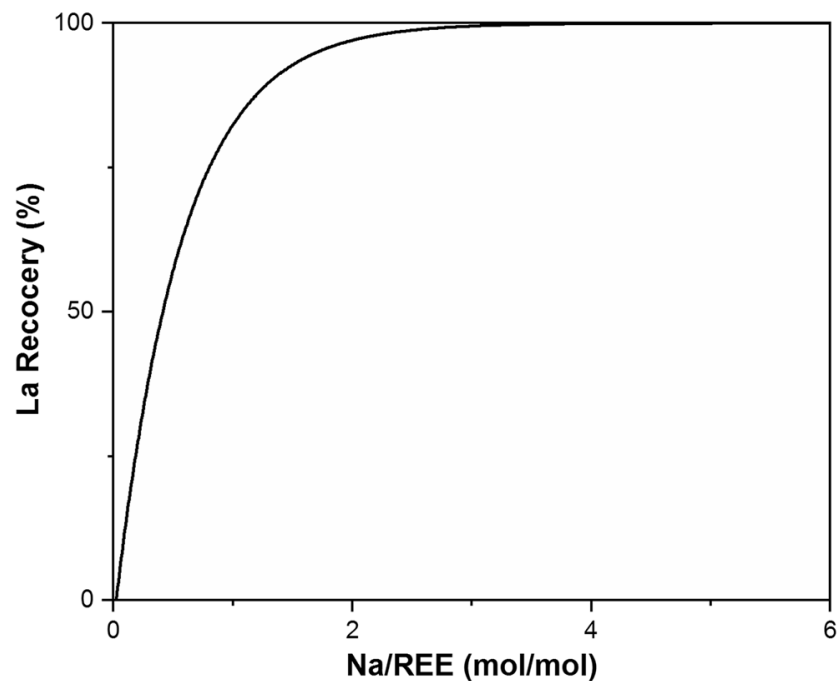

Fig. 2 An emulated precipitation curve fitted to experimental and synthetic data [20]

flowsheet model parameters, and hence model constraints, used to create the design of experiments are presented in Table 2 . The table only represents model constraints, not all the possible combinations of experiments. The cube points are experimental points of standard $x^{2}$ full factorial design with center points. Axial points are the extension of the factorial design into CCD [15].

\subsection{Experimental Verification of the Process Flowsheet}

Circulation experiments were performed in laboratory in order to demonstrate its viability in precipitation of REEs from the PLS with the recyclant solution. Leaching of sieved NiMH battery waste of $-0.5 \mathrm{~mm}$ size fraction was performed at room temperature in $2 \mathrm{M}$ $\mathrm{H}_{2} \mathrm{SO}_{4}$. A $1 \mathrm{~L}$ glass reactor was utilized with mechanical agitation (VWR VOS16, ca. $300 \mathrm{rpm}$ ). The sieved underflow sample weighed $45.8 \mathrm{~g}$. The density of the material was determined via water displacement method and was measured to be $c a .4 .7 \mathrm{~g} / \mathrm{cm}^{3}$. S/L ratio of $1 / 10$ was utilized. The $\mathrm{S} / \mathrm{L}$ was calculated as a ratio of sample mass and total volume of initial slurry: $448 \mathrm{~mL}$ of $2 \mathrm{M}$ acid was added into reactor. The sample was added carefully into the acidic solution due to potentially dangerous gas formation of $\mathrm{H}_{2}$ gas and runaway exothermic reaction. Once added, leaching was let to continue for $2 \mathrm{~h}$ after which PLS was filtered for the circulation experiments. The leach residue was washed with 100 $\mathrm{mL}$ distilled water $(100 \mathrm{~mL}$ vs $4.02 \mathrm{~g})$. Both the PLS and wash water composition are shown in Table 3. All the solutions obtained were analyzed by inductively coupled plasma-optical emission spectroscopy (ICP- 
Table 2 Parameter levels utilized to model REE recovery and conversion to hydroxides. The levels shown were used in the response surface design to create a fully quadratic model with second-degree interaction terms

\begin{tabular}{|c|c|c|c|c|c|c|}
\hline \multirow[t]{2}{*}{ Parameter code } & \multirow[t]{2}{*}{ Parameter } & \multicolumn{5}{|l|}{ Levels } \\
\hline & & Cube -1 & Cube +1 & Center & Axial -1 & Axial +1 \\
\hline $\mathrm{P} 1$ & {$\left[\mathrm{Na}_{2} \mathrm{SO}_{4}\right]$} & 0.5 & 2 & 1.25 & 0.5 & 2 \\
\hline $\mathrm{P} 2$ & Targeted $\mathrm{Na} / \mathrm{REE}$ mol ratio & 1 & 3 & 2 & 1 & 3 \\
\hline P3 & PLS [acid] (mol/h) & 0.5 & 4 & 2.25 & 0.5 & 4 \\
\hline P4 & PLS [REE] (mol/h) & 12 & 48 & 30 & 12 & 48 \\
\hline P5 & $\mathrm{L} / \mathrm{S}$ ratio & 12.5 & 100 & 56.25 & 12.5 & 100 \\
\hline P6 & $3 \mathrm{NaOH} / \mathrm{REE}$ (mol ratio) & 1 & 3 & 2 & 1 & 3 \\
\hline $\mathrm{P} 7$ & Bleed fraction $(\%)$ & 0 & 100 & 50 & 0 & 100 \\
\hline
\end{tabular}

OES, Perkin Elmer Optima 7100DV). Sodium was analyzed with flame atomic absorption spectroscopy (FAAS, Varian A240).

Initially, the maximum content of REEs was estimated by adding excessive quantity of $\mathrm{Na}_{2} \mathrm{SO}_{4}$. Eighty milliliters of PLS was mixed with $20 \mathrm{~mL}$ of $355 \mathrm{~g} / \mathrm{L}$ $\mathrm{Na}_{2} \mathrm{SO}_{4}$ solution. The collected, dry precipitate was weighed $(4.14 \mathrm{~g})$ and taken as a baseline $(4.14 \mathrm{~g}$ of DS per $80 \mathrm{~mL}$ of PLS) for a complete REE separation from the PLS, as REEs are known to precipitate in the presence of excessive amount of $\mathrm{Na}$ and $\mathrm{SO}_{4}$ [5]. This was later confirmed with the chemical analysis. Based on the mass of obtained double salt, the solution concentration of total REEs was calculated to be roughly $19.5 \mathrm{~g} / \mathrm{L}$.

In the circulation experiments, $40 \mathrm{~mL}$ of the recyclant was added to $60 \mathrm{~mL}$ of PLS. Leach residue and all precipitates were washed with distilled water. The wash water was heated up to $60{ }^{\circ} \mathrm{C}$. Vacuum filtration and filtration assembly was utilized in precipitate recovery and washing. Recycling was performed twice. In both double salt precipitation and rare earth hydroxide conversion, $T=60{ }^{\circ} \mathrm{C}$ was utilized for $2 \mathrm{~h}$ in a jacketed $100 \mathrm{~mL}$ glass reactor. Magnetic stirring was supplied to the reactor. The calculated, $\mathrm{Na} / \mathrm{REE}$ ratio in precipitation was roughly 2.32 and 2.04 in round 1 and round 2, respectively. The ratio was calculated based on known mass of the double sulfate and known quantity of $\mathrm{Na}$ in $\mathrm{NaOH}$ solution. In rare earth hydroxide conversion, L/S was not controlled, but $100 \mathrm{~mL}$
$\mathrm{NaOH}$ was mixed with the produced double salts. Mole ratio of $3 \mathrm{NaOH} / \mathrm{REE}=1.6$ was utilized, equaling to $c a .0 .35 \mathrm{M} 100 \mathrm{~mL} \mathrm{NaOH}$ solution.

\section{Results and Discussion}

It can be seen from Eqs. 1 and 2 that there is an imbalance between the stoichiometric requirements of $\mathrm{Na}^{+}$, $\mathrm{OH}^{-}, \mathrm{RE}^{3+}$, and $\mathrm{SO}_{4}{ }^{2-}$ ions. In each process cycle, according to Eq. 1, $1 \mathrm{~mol}$ of $\mathrm{Na}$ was required to produce $1 \mathrm{~mol}$ of double salt. Subsequently, additional $3 \mathrm{~mol}$ of $\mathrm{Na}$ per $1 \mathrm{~mol}$ of REE were added into the system during hydroxide conversion stage, resulting in $4 \mathrm{~mol}$ of $\mathrm{Na}$ per $1 \mathrm{~mol}$ of REE ratio in the process. However, it is commonly known that REE double salts are slightly soluble in sulfuric acid [7], and their precipitation efficiency can be improved via common ion effect by having an excess of sodium sulfate in the solution. It has been reported that to achieve $>95 \%$ double salt precipitation efficiency, a stoichiometric ratio (Na/REE) of 1 3 is required when operating at metal concentrations typical to NiMH battery recycling [20]. It is therefore advantageous for the process that ratio of $4 \mathrm{~mol} \mathrm{Na}$ per 1 mol of REE is maintained in the process circulation system.

Initially, fresh $\mathrm{Na}_{2} \mathrm{SO}_{4}$ is injected in the double salt precipitation tank to start the process. Based on Eqs. 1 and $2, \mathrm{Na} / \mathrm{REE}$ molar ratio of 1:4 can be achieved in one complete circulation cycle of the process. After the
Table 3 PLS and leach residue wash water analysis. The results are reported in $\mathrm{mg} / \mathrm{L}$

\begin{tabular}{lcccccccc}
\hline Solution & $\mathrm{Ni}$ & $\mathrm{Co}$ & $\mathrm{Mn}$ & $\mathrm{Al}$ & $\mathrm{Zn}$ & $\mathrm{Fe}$ & $\mathrm{La}$ & $\mathrm{Na}$ \\
\hline LR wash water (mg/L) & 3363 & 512 & 123 & 38.6 & 47.1 & 29.5 & 944 & 115 \\
PLS (mg/L) & 57752 & 7386 & 3528 & 1259 & 1857 & 601 & 9796 & 86 \\
\hline
\end{tabular}


initial batch of DS is produced, the sodium sulfate originating from the added $\mathrm{NaOH}$ in the double salt conversion to hydroxide is enough to fulfil the requirement for the double salt precipitation because of presence of the excess stoichiometry of $\mathrm{Na}$ with respect to REE (4:1 $\mathrm{Na} / \mathrm{REE}$ ratio). However, this will come at a cost of dilution of the main PLS. This is undesirable, as it will reduce the concentrations of valuable metals in the leach solution and ultimately, push the downstream processes to handle larger volumes. Furthermore, La loss will also increase in more diluted PLS due to its relatively high solubility in water and sulfuric acid, as shown by Lokshin et al. $\left(2.32 \mathrm{~g} / \mathrm{L}\right.$ in $\mathrm{H}_{2} \mathrm{O}$ at $\left.20^{\circ} \mathrm{C}\right)$ [7]. However, in this process flowsheet model, only stoichiometric ratio of $\mathrm{Na}$ and REE was taken into consideration in DS precipitation efficiency, not REE solubility, and same precipitation efficiency was assumed regardless of the REE concentration in the solution. By adjusting the $\mathrm{L} / \mathrm{S}$ ratio (liters of $\mathrm{NaOH}$ solution per $\mathrm{kg}$ of double salt) used in the double salt conversion to hydroxide, the magnitude of dilution factor can be affected. This trade-off of optimal L/S ratio will be investigated in this flowsheet simulation, and a regression model was built in order to find an optimal bleed fraction for different situations.

\subsection{Flowsheet Metamodeling Results}

The flowsheet model presented here has been simplified with several assumptions. (1) La is selected to represent all REEs as a group. (2) $\mathrm{Ni}$ is representing other metals that are soluble and will not be recovered in double salt precipitation stage. Ni concentration will act as an indicator of dilution due to recirculation. (3) Due to lack of electrolyte density data in the literature, the effect that the dissolved La will have on the density of the electrolyte will be estimated by using the value of $\mathrm{Al}_{2}\left(\mathrm{SO}_{4}\right)_{3}$ [21]. (4) Energy balance will not be considered in the model since the thermodynamic formation values for lanthanum double salt $\left(\mathrm{LaNa}\left(\mathrm{SO}_{4}\right)_{2} \cdot \mathrm{H}_{2} \mathrm{O}\right)$ were not found in the literature. It needs to be noted that the fitted regression model equations are not based on chemistry confirmed by the experimental work, but the literature.

The parameters given in Table 2 were used in Minitab to generate a DOE composed of CCD. The experimental matrix was entered into HSC SIM, and the resulting data originated from HSC simulation using process flowsheet shown in Fig. 1 was again entered back to Minitab. As a result, several models were created, each corresponding to a response. These were fully quadratic models that could be used to predict the responses in the whole precipitation system. Responses that are critical to the precipitation process itself and to the subsequent downstream unit processes were chosen such as $\mathrm{Na}_{2} \mathrm{SO}_{4}$ feed conc., dilution ratio, $\mathrm{Ni}$ and $\mathrm{Na}$ content in the PLS, produced REE precipitate, resulting $\mathrm{Na} / \mathrm{REE}$ ratio, and La loss in the process. The responses listed in Table 4 have a varying degree of importance to the process design. Response R1 is the descriptor for how much fresh sodium sulfate is required in order to achieve the set $\mathrm{Na} / \mathrm{REE}$ ratio (parameter P1). Negative number would indicate that there is an excess and the ratio has not been achieved, and a positive number would indicate that there is a need for fresh $\mathrm{Na}_{2} \mathrm{SO}_{4}$. Negative number would be an indication that the amount of $\mathrm{Na}$ in the system could be reduced by removing part of it by, e.g., bleeding it out (parameter P7) or by adjusting other process parameters, such as parameter P6. Response R2 is the descriptor for how much volume percentage of the recirculated $\mathrm{Na}_{2} \mathrm{SO}_{4}$ solution was bled out of the process. Response R3 is the $\mathrm{Ni}$ concentration in the raffinate after REE double salt precipitation. Observing $\mathrm{Ni}$ concentration is vital to the subsequent downstream extraction processes, as its dilution would indicate increased volumes. This may affect further solution purification, e.g., Ni precipitation or solvent extraction of other elements at later stages. Response R4 is the $\mathrm{Na}$ concentration in raffinate, and it is followed in the case of event of overly saturated solution conditions. R5 is the yield of double salt (D.S.) in $(\mathrm{kg} / \mathrm{h})$ that will enter the conversion unit process. This will be maximized. R6 is the actual achieved $\mathrm{Na} /$ REE ratio in the double salt precipitation process. There are situations where the combination of used parameters will not yield the desired $\mathrm{Na} / \mathrm{REE}$ ratio. Modeling this response helps in finding those constraints. R7 is the lost $\mathrm{La} \%$, i.e., the La that is not precipitated as double salt and will go downstream along with $\mathrm{Ni}$.

Firstly, quadratic regression models for each response (R1-R7) were created. CCD provides a quadratic model of following form:

$\mathrm{Y}=\beta_{0}+\sum_{i=1}^{k=7} \beta_{i} \cdot \mathrm{P}_{i}+\sum_{i=1}^{k=7} \beta_{i i} \cdot P_{i}^{2}+\sum_{1 \leq i \leq j}^{k=21} \beta_{i j} \cdot P_{i} P_{j}+\epsilon$

where $\beta_{\mathrm{i}}$ are the regression coefficients for the parameters $P_{\mathrm{i}}[15]$. The first term is the constant coefficient $\beta_{0}$, the second term represents the linear effects ( 7 in total), third term represents the polynomial effects ( 7 in total), and fourth term represents the second-order interactions (21 in total). In total, 35 terms consisting of linear, binomial, and second-order interactions must be considered. This is exemplified by the uncoded regression equation for raffinate Ni concentration, shown in Eq.5: 
Table 4 The selected responses and the stream or unit process from where the value of the response was recorded

\begin{tabular}{|c|c|c|c|c|c|c|c|}
\hline Response number & $\mathrm{R} 1$ & $\mathrm{R} 2$ & $\mathrm{R} 3$ & $\mathrm{R} 4$ & R5 & R6 & $\mathrm{R} 7$ \\
\hline Response content & $\begin{array}{l}\text { Fresh } \mathrm{Na}_{2} \mathrm{SO}_{4} \\
\quad \text { needed }(\mathrm{kg} / \mathrm{h})\end{array}$ & $\begin{array}{l}\text { Dilution Factor } \\
\text { (multiplier) }\end{array}$ & $\begin{array}{c}\text { Raff. Ni } \\
(\mathrm{g} / \mathrm{L})\end{array}$ & $\begin{array}{l}\text { Raff. Na } \\
\quad(\mathrm{g} / \mathrm{L})\end{array}$ & $\begin{array}{l}\text { D.S. produced } \\
(\mathrm{kg} / \mathrm{h})\end{array}$ & $\begin{array}{l}\text { Equilibrium Na/REE } \\
\quad(\mathrm{mol} / \mathrm{mol})\end{array}$ & $\begin{array}{l}\text { La lost } \\
(\%)\end{array}$ \\
\hline $\begin{array}{l}\text { Unit process or stream } \\
\text { where measured }\end{array}$ & $\begin{array}{l}\text { Precipitation } \\
\quad \text { Reactor \#1 }\end{array}$ & $\begin{array}{l}\text { Filtrate \#1 Precipitation } \\
\text { Reactor \#1 }\end{array}$ & $\begin{array}{c}\text { Filtrate } \\
\quad \# 1\end{array}$ & $\begin{array}{l}\text { Filtrate } \\
\quad \# 1\end{array}$ & Double salt & $\begin{array}{l}\text { Precipitation Reactor } \\
\quad \# 1\end{array}$ & $\begin{array}{r}\text { Input vs. } \\
\text { output }\end{array}$ \\
\hline
\end{tabular}

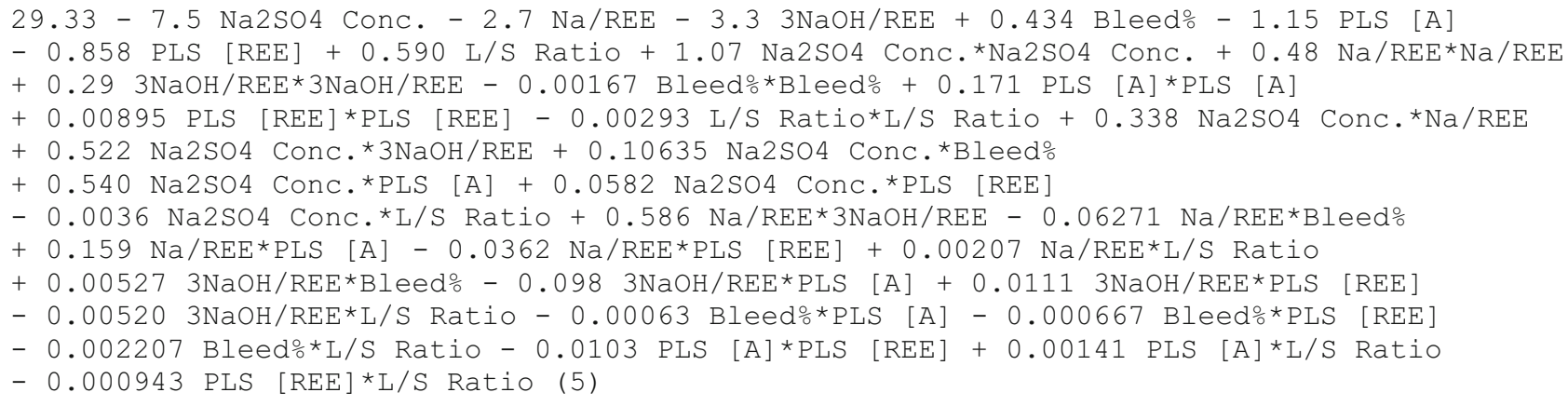

Due to the large amount of terms in the equations, the models for the other responses (R1-R2 and R4-R7), are not presented, instead, only results statistical analysis are shown.

In Table 5, the results are summarized for the created models for each investigated response. $S$ is the standard error of regression and $R^{2}$ (pred) is the predicted value. $R^{2}$ (pred) is obtained by the software removing observed data points, after which the model is refitted and the removed data point is compared to the refitted model. It can be seen that the regression and predictive power is relatively high ( $\geq 95 \%$ ) for each response except for responses $\mathrm{R} 1$ (fresh $\mathrm{Na}_{2} \mathrm{SO}_{4}$ needed), $\mathrm{R} 2$ (dilution factor), R3 (Ni concentration in raffinate), and R5 (D.S. produced). This may be due to the fact that a quadratic model is not sufficient to predict $\mathrm{La} \%$ losses due to many factors having simultaneous effect on the amount of $\mathrm{La} \%$ being lost. This is an inherent weakness in DOE-only

Table 5 Regression coefficients of the each response surface

\begin{tabular}{lcc}
\hline Response & $S$ & $R^{2}$ (pred) \\
\hline R1 & 1.39967 & $94.63 \%$ \\
R2 & 0.875865 & $85.30 \%$ \\
R3 & 2.7286 & $87.83 \%$ \\
R4 & 0.682155 & $97.25 \%$ \\
R5 & 2.38869 & $78.59 \%$ \\
R6 & 0.219010 & $99.62 \%$ \\
R7 & 0.0649982 & $99.87 \%$ \\
\hline
\end{tabular}

approach to process simulation optimization [22]. The use of only cube and axial points will cause smoothing of the data due to small number of levels (3) each parameter has. It is also possible that there are higher than second-degree interactions, causing flawed regression fitting. The face-centered CCD employed in this study has issues in detecting quadratic effects. Further improvements may be achieved by using other designs than CCD [23].

Once fitted, the models can be analyzed. As shown in Table 4, there are several responses that need to be optimized in the flowsheet model. Optimization of these parameters may be difficult manually due to many interdependencies of the different feed parameters. This will be especially true in more complex flowsheets. Minitab allows multi-parameter optimization, however as a result, there may be a large set of optimal parameters corresponding to the goals. It is up to the human operator to choose the criteria and weights for the multiparameter optimization and its results. The goal (G1-G8) of the optimization in this study is summarized in Table 6 . Certain responses are preferred to be minimized (raffinate volume, Na concentration in raffinate) or maximized (double salt yield, raffinate Ni concentration) or not optimized at all, based on the user preference. The optimization runs G1-G7 were single response optimizations which predict at what parameters values, it is possible to optimize one response at time. In optimization run G8, a multi-parameter optimization was performed. Simultaneously, two conflicting parameters were 
Table 6 Response optimization targets. Not opt. $=$ not optimized. Max. $=$ maximized Min. $=$ minimized

\begin{tabular}{|c|c|c|c|c|c|c|c|}
\hline $\begin{array}{l}\text { Experimental } \\
\text { code }\end{array}$ & $\begin{array}{l}\text { Fresh } \mathrm{Na}_{2} \mathrm{SO}_{4} \text { Needed } \\
(\mathrm{kg} / \mathrm{h})\end{array}$ & $\begin{array}{l}\text { Dilution factor } \\
\text { (multiplier) }\end{array}$ & $\begin{array}{l}\text { Raff. Ni } \\
(\mathrm{g} / \mathrm{L})\end{array}$ & $\begin{array}{l}\text { Raff. Na } \\
(\mathrm{g} / \mathrm{L})\end{array}$ & $\begin{array}{l}\text { D.S. produced } \\
(\mathrm{kg} / \mathrm{h})\end{array}$ & $\begin{array}{l}\text { Equilibrium } \mathrm{Na} / \mathrm{REE} \\
\text { (mol/mol) }\end{array}$ & $\begin{array}{l}\text { La lost } \\
(\%)\end{array}$ \\
\hline G1 & 0 & Not opt. & Not opt. & Not opt. & Not opt. & Not opt. & Not opt. \\
\hline G2 & Not opt. & Min. & Not opt. & Not opt. & Not opt. & Not opt. & Not opt. \\
\hline G3 & Not opt. & Not opt. & Max. & Not opt. & Not opt. & Not opt. & Not opt. \\
\hline G4 & Not opt. & Not opt. & Not opt. & Min. & Not opt. & Not opt. & Not opt. \\
\hline G5 & Not opt. & Not opt. & Not opt. & Not opt. & Max. & Not opt. & Not opt. \\
\hline G6 & Not opt. & Not opt. & Not opt. & Not opt. & Not opt. & 2 & Not opt. \\
\hline G7 & Not opt. & Not opt. & Not opt. & Not opt. & Not opt. & Not opt. & Min. \\
\hline G8 & 0 & Not opt. & Max. & Not opt. & Max. & 2 & Not opt. \\
\hline
\end{tabular}

optimized: Ni concentration in raffinate and the yield of double salt, both were maximized. These two goals are in conflict: in order to maximize the double salt yield, more $\mathrm{Na}$ is required. However, the use of recirculated solution as a source of $\mathrm{Na}$ will produce more dilute $\mathrm{Ni}$-containing raffinate. In this optimization run, the need for fresh $\mathrm{Na}_{2} \mathrm{SO}_{4}$ balance was also set to target a value of $0 \mathrm{t} / \mathrm{h}$. Negative value would indicate an excess of $\mathrm{Na}$ originating from the recirculation, and a positive value would indicate the needed quantity of fresh $\mathrm{Na}_{2} \mathrm{SO}_{4}$.

These data originated in experiments G1-G8 was then input in Minitab in order to find optimal solutions for desired responses, as shown in Tables 7 and 8. The results based on modeling are shown in Fig. 3. This optimization mainly explains that $74 \%$ of the solution must be bled out in order to satisfy the responses involving G8. The reason for model to predict that the optimal PLS acid concentration is high (4 M), is that the acid concentration would slightly affect the density of the solution, and hence, the Ni concentration present in equal volumes. $D$ is the desirability $(0-1)$, and shows how well the set goals were achieved in terms of response optimization. Since G1-G7 were single response optimizations, the desired result was always achieved. In Fig. 3, the optimization scenario (exp. G8) is described as seen in Minitab. The results clearly indicate that significant bleeding (47.6\%) of the recirculated solution will be required in order to limit excessive dilution of the raffinate, while simultaneously maintaining high enough $\mathrm{Na}(\mathrm{Na} / \mathrm{REE}=2.0)$ content by only using the recirculated solution (fresh $\mathrm{Na}=-0.294 \mathrm{~kg} / \mathrm{h}$ ) to cause satisfactory recovery of REEs as double salts $(12.44 \mathrm{~kg} / \mathrm{h})$. It can also be seen that increase in REE concentration of PLS will cause decrease in raffinate $\mathrm{Ni}$ concentration. The $\left[\mathrm{Na}_{2} \mathrm{SO}_{4}\right]$ has mostly no effect on anything as the source of $\mathrm{Na}$ is the recirculated solution (fresh $\mathrm{Na}_{2} \mathrm{SO}_{4}$ needed $=0$ ).

The results showed that combination of DOE and process flowsheet modeling can be a powerful tool to quickly identify possible bottlenecks in process design. However, response surface methodology in itself is not enough to create a robust regression model of the entire flowsheet. The future work on this model should involve extension and addition of downstream processes for the raffinate and the mixed rare earth hydroxide. Furthermore, the double salt conversion to hydroxide and other parts of the simulation can be further refined with experimental data on equilibration and kinetics to complete the full process design. Additionally, more appropriate designs should be considered in creating models that better conform to the higher order responses.

Table 7 Optimized parameters for investigated G1-G8

\begin{tabular}{|c|c|c|c|c|c|c|c|c|}
\hline $\begin{array}{l}\text { Experimental } \\
\text { code }\end{array}$ & $D$ & $\begin{array}{l}{\left[\mathrm{Na}_{2} \mathrm{SO}_{4}\right]} \\
(\mathrm{M})\end{array}$ & $\begin{array}{l}\text { Target Na/REE (mol/ } \\
\text { mol) }\end{array}$ & $\begin{array}{l}3 \mathrm{NaOH} / \mathrm{REE}(\mathrm{mol} / \\
\mathrm{mol})\end{array}$ & $\begin{array}{l}\text { Bleed } \\
\%\end{array}$ & $\begin{array}{l}\text { PLS [acid] } \\
\text { (M) }\end{array}$ & $\begin{array}{l}\text { PLS REE } \\
(\mathrm{g} / \mathrm{L})\end{array}$ & $\begin{array}{l}\mathrm{L} / \mathrm{S} \text { ratio } \\
(\mathrm{L} / \mathrm{kg})\end{array}$ \\
\hline G1 & 1.00 & 1.25 & 2.00 & 2.00 & 71.28 & 0.5 & 12.00 & 100.00 \\
\hline G2 & 1.00 & 2.00 & 1.00 & 1.63 & 100.0 & 4.00 & 12.00 & 40.78 \\
\hline G3 & 1.00 & 2.00 & 1.00 & 1.00 & 100.0 & 4.00 & 12.00 & 60.22 \\
\hline G4 & 1.00 & 2.00 & 1.00 & 1.00 & 100.0 & 0.5 & 12.00 & 100.00 \\
\hline G5 & 1.00 & 1.2576 & 3 & 2.03 & 2.02 & 2.27 & 48 & 55.81 \\
\hline G6 & 1.00 & 0.5 & 3.00 & 2.80 & 79.29 & 0.5 & 48 & 12.50 \\
\hline G7 & 1.00 & 1.2576 & 1.87 & 2.03 & 0.00 & 2.23 & 30.18 & 55.81 \\
\hline G8 & 0.88 & 2.00 & 1.9652 & 1.00 & 47.62 & 4.00 & 48 & 74.36 \\
\hline
\end{tabular}


Table 8 Results: the optimized responses, obtained by using parameters, Table 7

\begin{tabular}{|c|c|c|c|c|c|c|c|}
\hline $\begin{array}{l}\text { Experimental } \\
\text { code }\end{array}$ & $\begin{array}{l}\text { Fresh } \\
\mathrm{Na}_{2} \mathrm{SO}_{4} \\
\text { needed }(\mathrm{kg} / \\
\text { h) }\end{array}$ & $\begin{array}{l}\text { Dilution } \\
\text { factor } \\
\text { (multiplier) }\end{array}$ & $\begin{array}{l}\text { Raff. Ni } \\
(\mathrm{g} / \mathrm{L})\end{array}$ & $\begin{array}{l}\text { Raff. } \\
\mathrm{Na} \\
(\mathrm{g} / \mathrm{L})\end{array}$ & $\begin{array}{l}\text { D.S. } \\
\text { produced } \\
(\mathrm{kg} / \mathrm{h})\end{array}$ & $\begin{array}{l}\text { Equilibrium } \\
\mathrm{Na} / \mathrm{REE} \text { (mol/ } \\
\mathrm{mol} \text { ) }\end{array}$ & $\begin{array}{l}\text { La } \\
\text { lost } \\
(\%)\end{array}$ \\
\hline G1 & 0.00 & & & & & & \\
\hline G2 & & -0.4159 & & & & & \\
\hline G3 & & & 43.2563 & & & & \\
\hline G4 & & & & $\begin{array}{l}- \\
1.7- \\
92\end{array}$ & & & \\
\hline G5 & & & & & 13.2413 & & \\
\hline G6 & & & & & & 2 & \\
\hline G7 & & & & & & & $\begin{array}{l}- \\
2 .- \\
7- \\
54\end{array}$ \\
\hline G8 & -0.2939 & & 24.7581 & & 12.4446 & 2.0055 & \\
\hline
\end{tabular}

\subsection{Experimental Verification of the Process Flowsheet}

Experimental work was conducted in order to verify that the chemistry suggested by Eqs. 1 and 2 and flowsheet is valid and technically feasible. Before circulation experiments, $20 \mathrm{~mL}$ of $355 \mathrm{~g} / \mathrm{L} \mathrm{Na} \mathrm{Na}_{4} \mathrm{SO}_{4}$ was added to $80 \mathrm{~mL}$ of PLS. The obtained precipitate was the baseline mass $(4.11 \mathrm{~g})$ for the REE recovery. It was discovered with ICP-OES that the La yield was $99.1 \%$. Recirculation experiments were performed in two rounds. In the first round, the recyclant obtained from the initial conversion was used. The results clearly indicate that the circulation experiments can be performed with no carryover of impurities to recyclant as shown in Table 9 and Fig. 4. However, the wash waters of rare earth double sulfate both contained large quantities of base metals and rare earths. It is clear that vacuum was not sufficient in removing the remaining PLS from the double sulfate precipitate. Another key issue in the washing of the rare earth double sulfates is that they are slightly soluble in water [11]. It may be necessary to consider this by utilizing washing reagent where the solubility is minimized, e.g., hot water or hot sodium sulfate solution. It would also be beneficial to recycle the wash waters back to precipitation stage;
Fig. 3 Optimization results for the process flowsheet according to optimization settings of G8 as outlined in Table 6

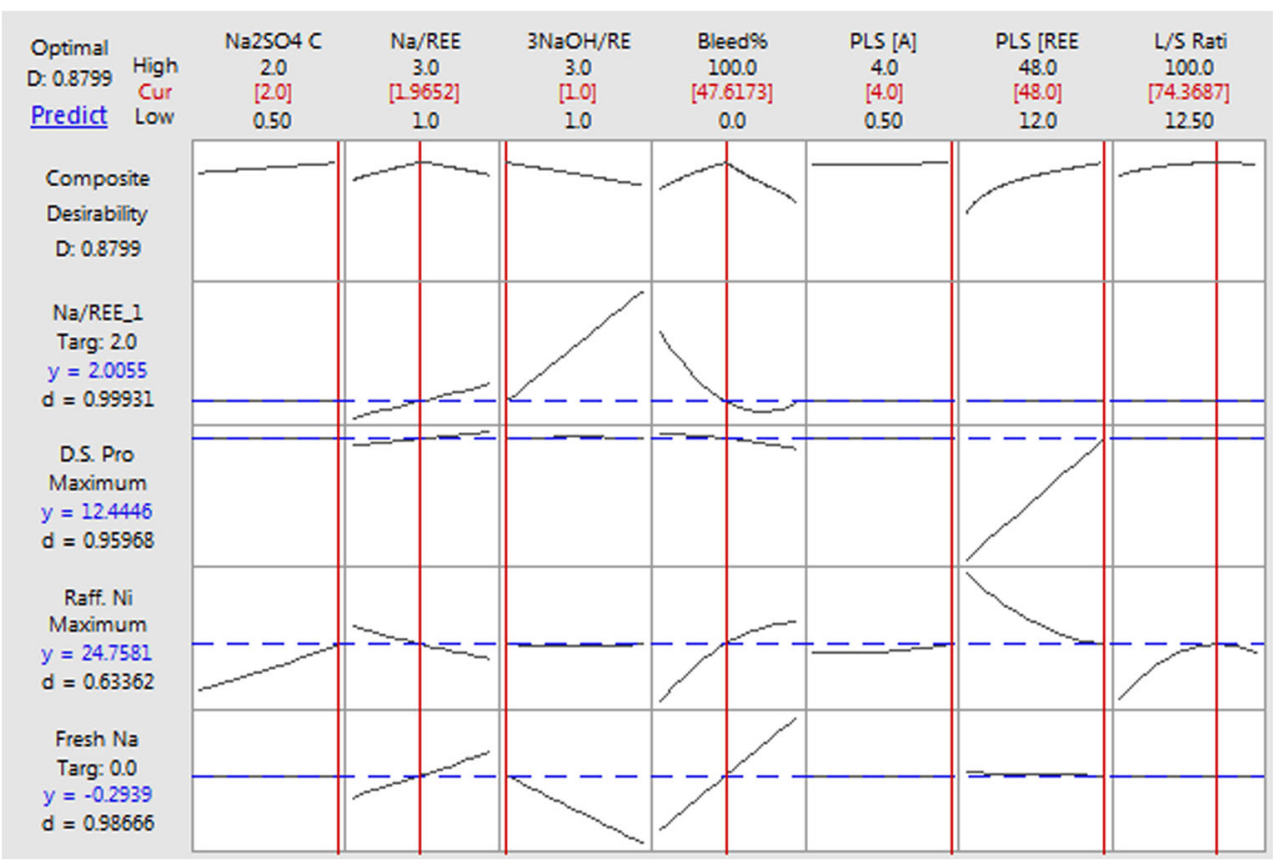


Table 9 Experimental input and output concentrations of elements in precipitation reactor (300-RC-001) and alkaline conversion reactor (300-RC002) when circulating the solution internally (round 1, round 2 ). n.a. = not analyzed

\begin{tabular}{|c|c|c|c|c|c|c|}
\hline \multirow{3}{*}{ ROUND 1} & \multicolumn{6}{|c|}{ Precipitation Reactor \#1 \& Filter \#1 } \\
\hline & \multicolumn{3}{|c|}{ Feed In } & \multicolumn{3}{|c|}{ Flow Out } \\
\hline & (A) & (B) & (C) & (D) & (E) & (F) \\
\hline Vol. (mL) & 60 & 40 & 50 & 50 & 94 & - \\
\hline Mass (g) & - & - & - & - & - & 2.74 \\
\hline $\mathrm{Ni}(\mathrm{mg} / \mathrm{L})$ & 57752 & $<1$ & n.a. & 979 & 35416 & n.a. \\
\hline $\mathrm{Co}(\mathrm{mg} / \mathrm{L})$ & 7386 & $<1$ & n.a. & 111 & 3951 & n.a. \\
\hline $\operatorname{Mn}(\mathrm{mg} / \mathrm{L})$ & 3528 & $<1$ & n.a. & 53.7 & 2627 & n.a. \\
\hline $\mathrm{Al}(\mathrm{mg} / \mathrm{L})$ & 1259 & $<1$ & n.a. & 20.3 & 797 & n.a. \\
\hline $\mathrm{Zn}(\mathrm{mg} / \mathrm{L})$ & 1857 & $<1$ & n.a. & 26.6 & 1330 & n.a. \\
\hline $\mathrm{Fe}(\mathrm{mg} / \mathrm{L})$ & 601 & $<1$ & n.a. & 8.3 & 410 & n.a. \\
\hline $\mathrm{La}(\mathrm{mg} / \mathrm{L})$ & 9796 & $<1$ & n.a. & 462 & 195 & n.a. \\
\hline $\mathrm{Na}(\mathrm{mg} / \mathrm{L})$ & 86 & $>0.53 \mathrm{M}$ & n.a. & 240 & 4702 & n.a. \\
\hline $\mathrm{S}(\mathrm{mg} / \mathrm{L})$ & n.a. & 6740 & n.a. & n.a. & n.a. & n.a. \\
\hline
\end{tabular}

\begin{tabular}{|c|c|c|c|c|c|c|}
\hline \multirow{3}{*}{ ROUND 1} & \multicolumn{6}{|c|}{ Alkaline Conversion Reactor \#1 \& Filter \#2 } \\
\hline & \multicolumn{3}{|c|}{ Feed In } & \multicolumn{3}{|c|}{ Flow Out } \\
\hline & (F) & (G) & (H) & (I) & (K) & $(\mathbf{J})$ \\
\hline Vol. (mL) & - & 100 & 50 & 50 & 94 & - \\
\hline Mass $(\mathrm{g})$ & 2.74 & - & - & - & - & 2.09 \\
\hline $\mathrm{Ni}(\mathrm{mg} / \mathrm{L})$ & n.a. & n.a. & n.a. & $<1$ & $<1$ & n.a. \\
\hline $\mathrm{Co}(\mathrm{mg} / \mathrm{L})$ & n.a. & n.a. & n.a. & $<1$ & $<1$ & n.a. \\
\hline $\mathrm{Mn}(\mathrm{mg} / \mathrm{L})$ & n.a. & n.a. & n.a. & $<1$ & $<1$ & n.a. \\
\hline $\mathrm{Al}(\mathrm{mg} / \mathrm{L})$ & n.a. & n.a. & n.a. & $<1$ & $<1$ & n.a. \\
\hline $\mathrm{Zn}(\mathrm{mg} / \mathrm{L})$ & n.a. & n.a. & n.a. & $<1$ & $<1$ & n.a. \\
\hline $\mathrm{Fe}(\mathrm{mg} / \mathrm{L})$ & n.a. & n.a. & n.a. & $<1$ & $<1$ & n.a. \\
\hline $\mathrm{La}(\mathrm{mg} / \mathrm{L})$ & n.a. & n.a. & n.a. & $<1$ & $<1$ & n.a. \\
\hline $\mathrm{Na}(\mathrm{mg} / \mathrm{L})$ & n.a. & $0.35 \mathrm{M}$ & n.a. & n.a. & $>0.35 \mathrm{M}$ & n.a. \\
\hline $\mathrm{S}(\mathrm{mg} / \mathrm{L})$ & n.a. & n.a. & n.a. & n.a. & 4580 & n.a. \\
\hline
\end{tabular}

\begin{tabular}{|l|ccc|ccc|}
\multirow{2}{*}{ ROUND 2} & \multicolumn{5}{|c|}{ Precipitation Reactor \#1 \& Filter \#1 } \\
\cline { 2 - 7 } & \multicolumn{7}{c|}{ Feed In } & (B) & (C) & (D) & (E) & (F) \\
\hline Vol. $(\mathrm{mL})$ & 60 & 40 & 50 & 50 & 94 & - \\
$\mathrm{Mass}(\mathrm{g})$ & - & - & - & - & - & 2.56 \\
$\mathrm{Ni}(\mathrm{mg} / \mathrm{L})$ & 57752 & $<1$ & n.a. & 1147 & 35576 & n.a. \\
$\mathrm{Co}(\mathrm{mg} / \mathrm{L})$ & 7386 & $<1$ & n.a. & 134 & 3958 & n.a. \\
$\mathrm{Mn}(\mathrm{mg} / \mathrm{L})$ & 3528 & $<1$ & n.a. & 49.4 & 2312 & n.a. \\
$\mathrm{Al}(\mathrm{mg} / \mathrm{L})$ & 1259 & $<1$ & n.a. & 18.5 & 694 & n.a. \\
$\mathrm{Zn}(\mathrm{mg} / \mathrm{L})$ & 1857 & $<1$ & n.a. & 23.5 & 1163 & n.a. \\
$\mathrm{Fe}(\mathrm{mg} / \mathrm{L})$ & 601 & $<1$ & n.a. & 5.2 & 354 & n.a. \\
$\mathrm{La}(\mathrm{mg} / \mathrm{L})$ & 9796 & $<1$ & n.a. & 463 & 449 & n.a. \\
$\mathrm{Na}(\mathrm{mg} / \mathrm{L})$ & 86 & $>0.35 \mathrm{M}$ & n.a. & 197 & 1903 & n.a. \\
$\mathrm{S}(\mathrm{mg} / \mathrm{L})$ & n.a. & 4580 & n.a. & n.a. & n.a. & n.a. \\
\hline
\end{tabular}




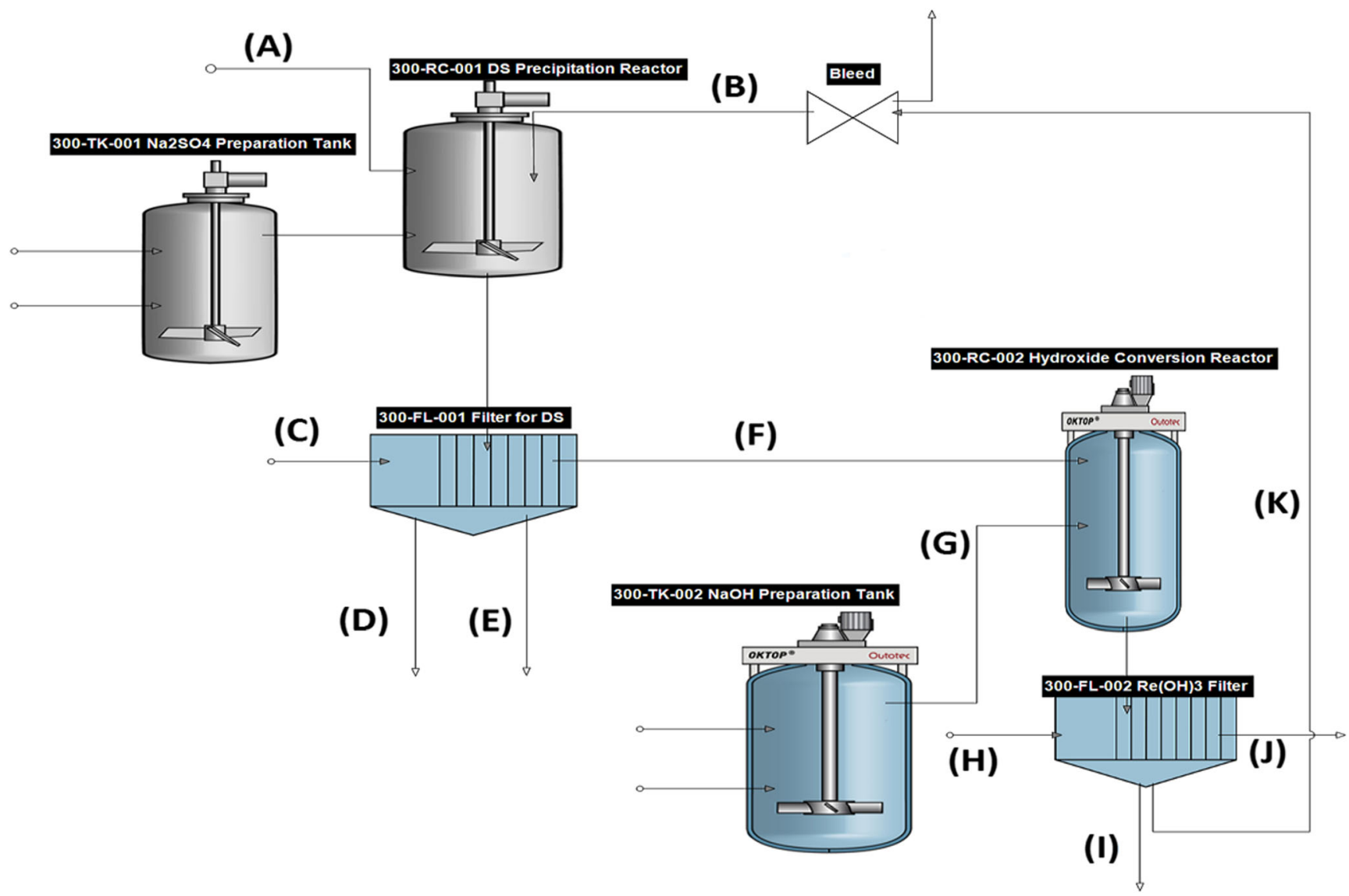

Fig. 4 Stream locations that are being depicted in Table 9

however, this would amount to dilution of the PLS which might be undesirable. $60{ }^{\circ} \mathrm{C}$ wash water was utilized in this study; however, some losses still occurred. The contents of $\mathrm{La}$ in the wash water is higher in relation to other metals than in the leach residue wash water $(0.17$ vs. $0.47 \mathrm{La} / \mathrm{Ni})$ - an indication that some of the double salts may have dissolved, regardless of the $60{ }^{\circ} \mathrm{C}$ wash water. Unsurprisingly, $\mathrm{NaOH}$ solutions were devoid of metals as the measured $\mathrm{pH}$ of these solutions was 13 after the conversion. No
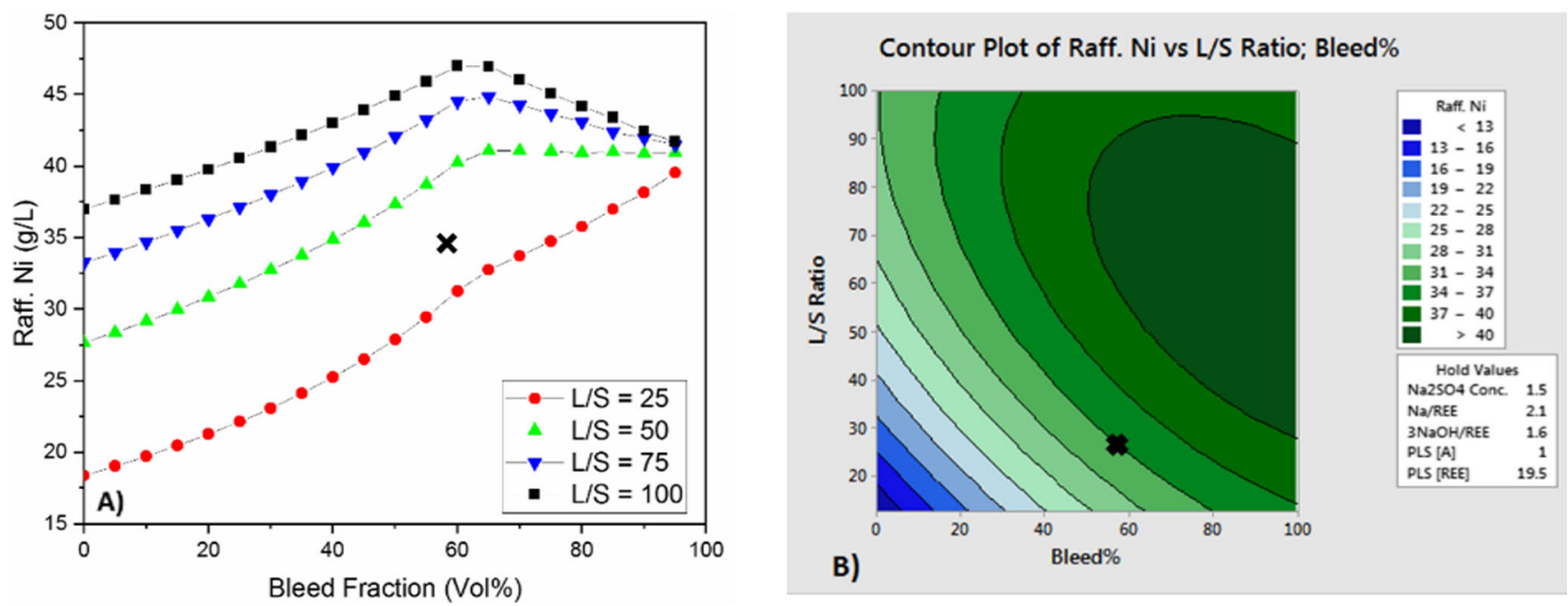

Fig. 5 The flowsheet model results (a) and metamodel results (b) at identical hold values. X marks the real experimental results 
dissolved aluminum was found either. The sulfur content found in these solutions mirrors the dissociation of the REE double salt and its subsequent hydrolytic precipitation. By calculating the mole quantity of $S$ in round 1 recyclant $(14 \mathrm{mmol})$, one can find that the amount of $S$ mirrors the amount of double sulfate (2.74 $\mathrm{g}$ of feed D.S. vs. $2.66 \mathrm{~g}$ D.S. based on sulfur content) that was fed to the experiments. The yield of lanthanum changed between round 1 and round 2 (96.9\% and $92.8 \%$ respectively). This can be attributed to Eqs. (1) and (2): the amount of double sulfate obtained was less, and since rigid $3 \mathrm{NaOH} / \mathrm{REE}=1.6$ ratio was used, the $\mathrm{Na}$ concentration in $\mathrm{NaOH}$ solution was less as it was subsequently too in the recyclant between the two experiments, decreasing the saturation degree in precipitation. This shows that the principle chemistry of flowsheet using the $\mathrm{Na}$ and $\mathrm{SO}_{4}$ containing solution originating from the double salt conversion as a precipitation agent is valid. Utilization of this method will have potential to drastically reduce the consumption of $\mathrm{Na}$ in the processing of NiMH battery waste.

\subsection{Observed, Modeled, and Metamodeled}

The results showed that combination of DOE and process flowsheet modeling can be a tool to quickly identify possible bottlenecks in process design. However, response surface methodology in itself is not enough to create a robust regression model of the flowsheet. This can be used for early evaluation of the process optimization, to be further verified by experimental work in the desired conditions. Experimental work conducted verified that the modeled chemistry works in the laboratory scale and that recirculation of the process solution can result in internal usage of $\mathrm{Na}$ as precipitation agent for REE. To illustrate this, Fig. 5 shows the comparison of data from flowsheet model (Fig. 5a) and metamodel (Fig. 5b) at process held process condition. In this investigation, the effect of $\mathrm{L} / \mathrm{S}$ ratio and bleed fraction (\%) on raffinate $\mathrm{Ni}$ concentration is investigated. The experiments conducted at shown hold conditions show that it is in good agreement with the model however with slight variation. The experiments were performed at $\mathrm{L} / \mathrm{S}=\sim 28$, and $\mathrm{Ni}$ in raffinate was 35 $\mathrm{g} / \mathrm{L}$ after precipitation experiments as shown in Table 9.

The future work on this model should involve extension and addition of downstream processes for the raffinate and the mixed rare earth hydroxide. Furthermore, the double salt conversion to hydroxide and other parts of the simulation can be further refined with experimental data on equilibration and kinetics to complete the full process design. Additionally, more appropriate designs should be considered in creating models that better conform to the higher order responses.
Furthermore, the optimization work can be improved by iteratively looking at ever smaller parameter space.

\section{Conclusions}

The current study was conducted in order to optimize chemical consumption in future NiMH recycling process: $\mathrm{NiMH}$ leaching, REE DS precipitation- $\mathrm{NaOH}$ conversion of REEs. Tools used to study the process, specifically internal solution circulation were HSC Sim and Minitab. Further the model was compared to experimental data.

Firstly, a process flowsheet was successfully designed for recirculation of sodium-rich solution originated in REE hydroxide conversion step during NiMH battery wastes treatment using HSC Sim software. Design of experiments was utilized in analyzing the variability in several responses (fresh $\mathrm{Na}_{2} \mathrm{SO}_{4}$ balance $(\mathrm{kg} / \mathrm{h})$, dilution factor, raffinate $\mathrm{Ni}$ conc. $(\mathrm{g} / \mathrm{L})$, raffinate $\mathrm{Na}$ conc. $(\mathrm{g} / \mathrm{L})$, double salt produced $(\mathrm{kg} / \mathrm{h})$, and La lost\%) in the created flowsheet simulation model. By combining these methods, it was possible to acquire information on how to optimize the re-use of sodium and sulfate ions present in the rare earth double sulfate. CCD was employed in forming quadratic regression models for the responses. Generally, good regression $\left(R^{2}>95 \%\right)$ was achieved for most of the responses, but results for some response models ( $\mathrm{La}$ lost $\%, \mathrm{R} 7)$ were not optimal, indicating that quadratic models were not able to model all the responses. Furthermore, the researcher must understand the limitation of applying CCD, namely, the model being (a) polynomial in form and (b) its tendency to smooth out the data. It was shown that combination of process simulation, DOE, and statistical software can be useful to identify bottlenecks in a simple process model. In order to maximize the Ni concentration in the raffinate, along with maximal double salt production and optimal $\mathrm{Na}$ usage, $47 \%$ of the recirculated solution must be bled out of the loop.

Secondly, experiments were performed in observing whether recycling the solutions would be technically viable and to compare one experimental point/result with the modeled conditions. Solutions could be successfully recirculated, and the yield of La was between $90-95 \%$. The yield depended upon the $\mathrm{NaOH}$ concentration and $\mathrm{S} / \mathrm{L}$ ratio used in double salt conversion as it directly affects the $\mathrm{Na}$ concentration of the recyclant. The results suggest that metamodeling of flowsheet model and process flowsheet modeling can be a powerful tool to quickly identify possible behavior in the process design. However, in the development of real hydrometallurgical recycling process, it is essential to conduct real experiments in the defined conditions in order to verify the functionality of the said flowsheet. It was shown in this work that circulation flowsheet was functional, albeit at the cost of dilution. 
Acknowledgements Open access funding provided by Aalto University.

Funding Information The authors received funding from MineWEEE (grant number 7100/31/2016) (VA), CMEco (grant number 7405/31/ 2016) (ML), and BATCircle (grant number 4853/31/2018) (ML), all funded by Business Finland. The research was also supported by the Strategic Research Council at the Academy of Finland, project CloseLoop (grant number 303454) (AP). Also the collaboration with HYMAG project (SL/84/04.03.00.0400/2017) (ML), funded by Satakuntaliitto, is received. RawMatTERS Finland Infrastructure (RAMI) funded by Academy of Finland is also received (all authors).

\section{Compliance with Ethical Standards}

Conflict of Interest The authors declare that they have no conflict of interest.

Open Access This article is distributed under the terms of the Creative Commons Attribution 4.0 International License (http:// creativecommons.org/licenses/by/4.0/), which permits unrestricted use, distribution, and reproduction in any medium, provided you give appropriate credit to the original author(s) and the source, provide a link to the Creative Commons license, and indicate if changes were made.

\section{References}

1. Larsson K, Ekberg C, Ødegaard-Jensen A (2013) Dissolution and characterization of HEV NiMH batteries. Waste Manag 33:689698

2. Pietrelli L, Bellomo B, Fontana D, Montereali MR (2002) Rare earths recovery from NiMH spent batteries. Hydrometallurgy. 66: 135-139

3. Zhang P, Yokoyama T, Itabashi O, Wakui Y, Suzuki TM, Inoue K (1999) Recovery of metal values from spent nickel-metal hydride rechargeable batteries. J Power Sources 77:116-122

4. Rodrigues LEOC, Mansur MB (2010) Hydrometallurgical separation of rare earth elements, cobalt and nickel from spent nickelmetal-hydride batteries. J Power Sources 195:3735-3741

5. Porvali A, Wilson BP, Lundström M (2018) Lanthanide-alkali double sulfate precipitation from strong sulfuric acid NiMH battery waste leachate. Waste Manag 71:381-389

6. Dean JA, Lange NA (1999) Lange's Handbook of Chemistry. 15th Ed. New York: McGraw-Hill.

7. Lokshin EP, Tareeva OA, Ivlev KG, Kashulina TG (2005) Solubility of double alkali metal $(\mathrm{Na}, \mathrm{K})$ rare-earth ( $\mathrm{La}, \mathrm{Ce}$ ) sulfates in sulfuric-phosphoric acid solutions at 20 C. Russian J Appl Chem 78:1058-1063

8. Senanayake G, Jayasekera S, Bandara AMTS, Koenigsberger E, Koenigsberger L, Kyle J (2016) Rare earth metal ion solubility in sulphate-phosphate solutions of $\mathrm{pH}$ range -0.5 to 5.0 relevant to processing fluorapatite rich concentrates: effect of calcium, aluminium, iron and sodium ions and temperature up to $80^{\circ} \mathrm{C}$. Miner Eng 98:169-176

9. Innocenzi V, Vegliò F (2012) Recovery of rare earths and base metals from spent nickel-metal hydride batteries by sequential sulphuric acid leaching and selective precipitations. J Power Sources 211:184-191

10. Bertuol DA, Bernardes AM, Tenório JAS (2009) Spent NiMH batteries - the role of selective precipitation in the recovery of valuable metals. J Power Sources 193:914-923

11. Das G, Lencka MM, Eslamimanesh A, Wang P, Anderko A, Riman RE, Navrotsky A (2019) Rare earth sulfates in aqueous systems: thermodynamic modeling of binary and multicomponent systems over wide concentration and temperature ranges. J Chem Thermodyn 131:49-79

12. Sastri VR, Perumareddi JR, Rao VR, Rayudu GVS, Bünzli JCG (2003) Modern Aspects of Rare Earths and their Complexes. Amsterdam: Elsevier

13. Abreu RD, Morais CA (2010) Purification of rare earth elements from monazite sulphuric acid leach liquor and the production of high-purity ceric oxide. Miner Eng 23:536-540

14. Kleijnen JPC (2017) Regression and Kriging metamodels with their experimental designs in simulation: a review. Eur J Oper Res 256: $1-16$

15. Bezerra MA, Santelli RE, Oliveira EP, Villar LS, Escaleira LA (2008) Response surface methodology (RSM) as a tool for optimization in analytical chemistry. Talanta 76:965-977

16. Byrne RP, Bogle IDL (2000) Global optimization of modular process flowsheets. Ind Eng Chem Res 39:4296-4301

17. Kleijnen JPC (2008) Response surface methodology for constrained simulation optimization: an overview. Simul Model Pract Theory 16:50-64

18. Outotec, HSC Chemistry (2018) 9.4.1, https://www.outotec.com/ products/digital-solutions/hsc-chemistry/

19. Minitab Inc (2018), Minitab 17.1., https://www.minitab.com/en-us/

20. Kul M, Topkaya Y, Karakaya İ (2008) Rare earth double sulfates from pre-concentrated bastnasite. Hydrometallurgy. 93:129-135

21. Laliberte M, Cooper WE (2004) Model for calculating the density of aqueous electrolyte solutions. J Chem Eng Data 49:1141-1151

22. Kleijnen JPC (1998) 'Design of Experiments', in Banks J (ed.) Handbook of Simulation - Principles, Methodology, Advances, Applications, and Practice, John Wiley \& Sons.

23. Kleijnen JPC (2005) An overview of the design and analysis of simulation experiments for sensitivity analysis. Eur J Oper Res 164:287-300

Publisher's Note Springer Nature remains neutral with regard to jurisdictional claims in published maps and institutional affiliations. 